UC-NRLF

|

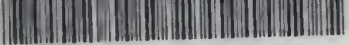

B 3 07] 6] 3 


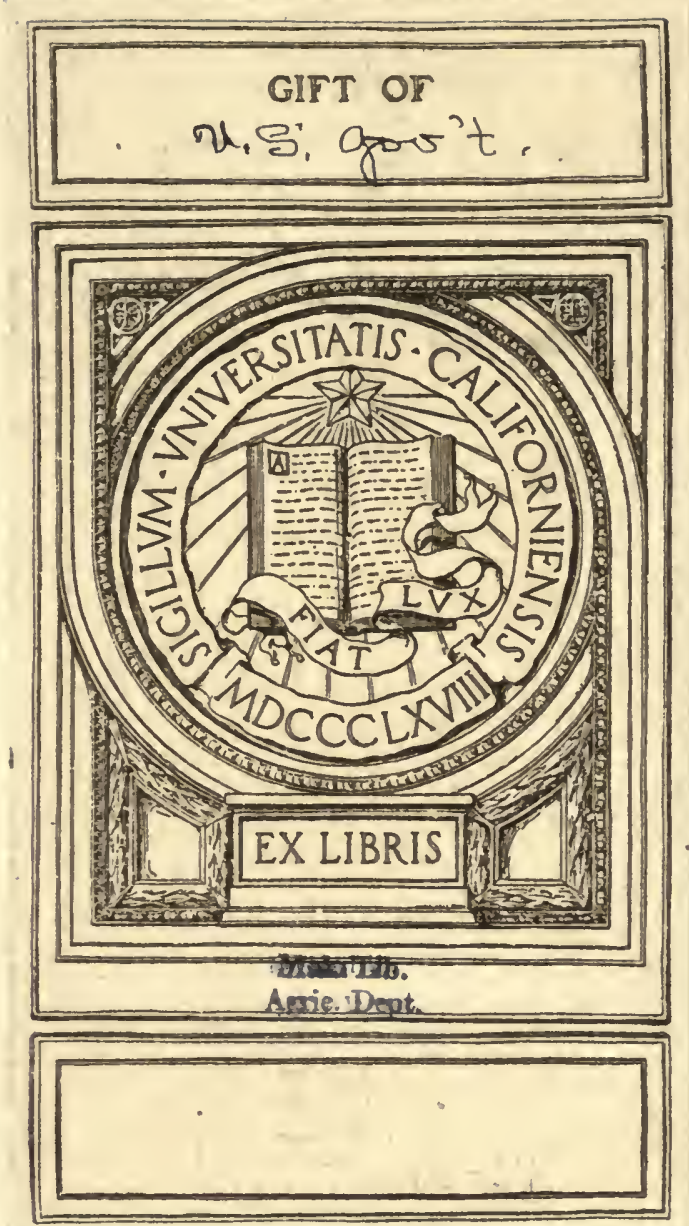


Digitized by the Internet Archive in 2007 with funding from Microsoft Corporation 
The following table shows the texture of soil as it generally occurs in Lancaster County:

Mechanical analyses of Cecil silt loam.

\begin{tabular}{|c|c|c|c|c|c|c|c|c|c|}
\hline No. & Locality. & Description. & 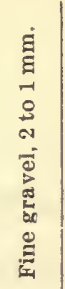 & 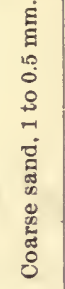 & 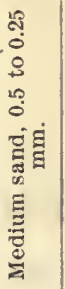 & 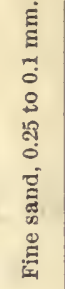 & 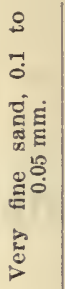 & 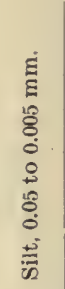 & 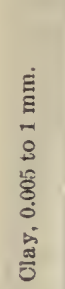 \\
\hline & & & P.ct. & P.ct. & P.ct. & P.et. & P.ct. & P.et. & P. ct. \\
\hline 11830 & $\begin{array}{l}4 \text { miles NE. of Lan- } \\
\text { caster. }\end{array}$ & Silty loam, 0 to 16 inches -. & 2.9 & 3.9 & 1.4 & 5.0 & 16.3 & 61.6 & 8.6 \\
\hline 11828 & $\begin{array}{l}\text { mile S. of Lan- } \\
\text { caster. }\end{array}$ & Silty loam, 0 to 12 inches.. & 3.3 & 5.7 & 1.8 & 4.3 & 16.4 & 54.6 & 13.9 \\
\hline 11826 & 2 miles N. of Primus. & Silty loam. 0 to 16 inches.- & 1.3 & 1.4 & .7 & 2.9 & 9.4 & 68.4 & 15.7 \\
\hline 11827 & Subsoil of 11826 & $\begin{array}{l}\text { Yellow silty clay, } 16 \text { to } 30 \\
\text { inches. }\end{array}$ & 1.7 & 4.0 & 1.4 & 4.3 & 8.6 & 50.1 & 29.4 \\
\hline 11831 & Subsoil of 11830 & $\begin{array}{l}\text { Yellow silty clay, } 16 \text { to } 36 \\
\text { inches. }\end{array}$ & 1.3 & 2.3 & .9 & 3.0 & 9.1 & 53.1 & 30.0 \\
\hline 11829 & Subsoll of 11828 & $\begin{array}{l}\text { Yellow silty clay, } 12 \text { to } 36 \\
\text { inches. }\end{array}$ & 1.0 & 2.1 & .9 & 2.3 & 8.4 & 50.4 & 34.7 \\
\hline
\end{tabular}

SURFACE FEATURES AND DERIVATION OF SOIL.

The surface features of the farm are simple and consist of a ridge, along the crest of which runs the public road. This ridge slopes away on each side to other ridges, from which it is separated by erosion valleys occupied by small streams flanked by narrow belts of bottom lands. Tributary to these small streams are many small gullies, which carry water only after a rain. They usually enter the streams nearly at right angles and if unchecked succeed in rapidly eating their way in $V$-shaped troughs nearly to the top of the ridge, eroding the soil and forming unproductive galls. This has the effect of leaving a series of smaller ridges flanking the main ridge nearly at right angles. The larger and steeper of the ravines between these small ridges are allowed to remain in the growth of small pine and other trees which covers them, but the farther encroachment of the smaller ones is prevented by means of terracing, ditching, and filling with brush, and the larger ones are being reclaimed from the top as fast as these methods become effective enough to allow it. The plantation has a range of elevation of possibly 100 feet from the lowest creek to the highest point on the public road. Those lands north of the road drain into Hannas Creek, while south of the road the principal drainage is into a small branch nearly south from the house.

The soils are derived from ancient crystalline and metamorphic rocks by residual weathering or, as in the case of the'stream bottoms, by wash from the hills. The rocks at this point are mostly highly weath- 
ered micaceous and talcose schists having a nearly vertical dip and north and south strike. The resulting soils are yellow and gray heavy loams with massive light-red clay subsoils. Quartz veins are of frequent occurrence and from their resistance to the forces of weathering many angular fragments of this rock are found in the soil which immediately overlies them, rendering tillage difficult at these points. Where thoroughly tilled these areas are fully as productive as the surrounding stone-free soils.

With the exception of a few narrow stream bottoms, the whole area is high lying and well drained. One of the greatest problems is to prevent erosion in the cultivated fields and to produce a sufficient depth of soil in those places where the soil has been washed away and the subsoil exposed.

\section{DESCRIPTION OF THE SOIL.}

Only one type of soil of any importance occurs on the place. The only variations which can be detecteel are the stony areas mentioned and the galled spots, where some or all of the soil has been removed. These are constantly changing, some being reclaimed by cultivation and new ones being formed by destructive rains.

The soil of the Cecil silt loam, as found in this plantation, has an average depth of 6 inches, and is a yellowish-brown or gray mellow silt loam, usually free from stone. It contains sufficient clay to clod and bake badly if stirred in too wet condition, but if plowed in proper moisture condition it is mellow and fine. The subsoil to more than 3 feet deep is a bright-red, massive silty clay loam or clay, crumbling readily when dry, especially in the upper portion, but becoming more plastic and tenacious in the lower. The soil is usually thinner on the crest of a slope than on the top of the ridge or the lower part of the slope.

The whole type is well drained; in fact, the surface drainage is too rapid with the usual heavy rainfall. Both soil and subsoil are of such texture as to be capable of holding sufficient moisture to mature crops requiring a long growing season and large amounts of moisture; but under the superficial tillage usually given they sometimes suffer from lack of moisture, which has been allowed to escape by evaporation from the baked surface.

\section{CROPS GROWN AND AVERAGE YIELDS.}

Cotton is the chief crop and yields on the average about one-third bale per acre. It may reach one-half bale on newly cleared lands, but falls below one-third on those portions worked on shares by tenants. Corn is not grown extensively on the upland, but stands next in importance to cotton and yields from 10 to 30 bushels per acre. Some oats, sorghum, and peas are grown, but do not receive the attention they should. 


\section{MANAGEMENT OF PLANTATION.}

The principal aim in the management of this farm is stock raising; not alone for the direct profit derived, but also for the benefits which will accrue to the lands from this practice. As a consequence much of the land is pasture, the grasses consisting of native wild varieties and some Bermuda grass. In addition to cotton and corn, other crops are grown as follows: Peas, 10 acres; corn with peas, 30 acres ; oats, 15 acres; and sorghum, 10 acres - all of which are used as grain and fodder for the stock. There are on the farm 60 to 100 head of grade cattle suitable for both dairy and beef purposes. These animals are stabled from October until April and penned at night during the remainder of the year. There are also 20 to 25 head of sheep, which are stabled the same as the cattle; 3 to 6 hogs, and a small flock of poultry. The working stock consists of 8 mules, 4 horses, and 2 colts. The stable manure is hauled to the fields in the spring and made to cover from 30 to 40 acres. In addition to the barnyard manure, commercial fertilizer is also applied at planting time. This consists of cotton-seed meal, rock phosphate, and kainit, combined so as to give 8.6 per cent phosphoric acid, 3 per cent ammonia, and 3 per cent potash. It is used for the cotton crop at the rate of 200 to 300 pounds to the acre.

The tillage is done chiefly with one-horse implements and much hand labor is used in the operation of thinning and hoeing the principal crops. No definite system of rotation of crops is followed. All of the upland fields are occasionally changed from cotton to corn and back again to cotton. Live-stock farming, such as is being conducted on this farm, is seldom seen in Lancaster County, and there is no doubt that it will prove highly profitable and be the means of greatly improving the productivity of the soils. The methods undertaken are commendable, but could be very much improved by the introduction of modern farm implements for the better cultivation of the soil, by the adoption of a suitable system of rotation of crops, and by the successful extension of permanent pasture and the production of more forage crops for the live stock. The acreage of cowpeas could be profitably increased, and winter cover-crops of rye and barley would prove economical.

RESULTS OF DIFFERENT MANURIAL TREATMENTS OF CECIL SILT LOAM.

The method used in making the following determinations is known as the wire-basket method, and consists of growing wheat plants in small wire baskets containing the soil to be experimented with. After the baskets have been filled with soil and planted to wheat, they are sealed with paraffin, so that there is little loss of water directly from the soil. By weighing the baskets periodically and adding distilled water from time to time a favorable moisture content of the soil is maintained, and the amount of water transpired by the plants is ascertained. The 
time required for a test of this kind is twenty to twenty-five days, at the close of which period both the green weight and transpiration of the plants are ascertained. A fuller description of the method is given in Circular No. 15 of this Bureau.

The sample of soil used in this instance is a composite. It was taken to a depth of 6 inches. In 1903 the soil was broken about 6 inches deep, and treated with stable manure at the rate of 8 loads per acre, and also with 200 pounds of the fertilizer already described. The yield for that year was about 700 pounds of seed cotton per acre. In 1904 the soil was broken a little deeper than in the preceding year, and was given the same amount of stable manure and 300 pounds per acre of the fertilizer above mentioned. The result was a yield of 800 to 850 pounds of seed cotton per acre.

The following table shows the results of the wire-basket experiment, the relative growth of plants being expressed on the basis of 100 for the untreated soil :

Relative growth of wheat plants on Cecil silt loam with various treatments.

\begin{tabular}{|c|c|}
\hline Fertilizing materials and quantity applied per acre. & $\begin{array}{l}\text { Relative } \\
\text { growth. }\end{array}$ \\
\hline 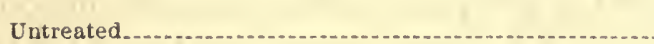 & 100 \\
\hline 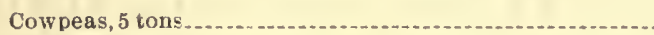 & 236 \\
\hline Cowpeas, $2 \frac{1}{2}$ tons & 181 \\
\hline Nitrate of soda, 200 pounds & 175 \\
\hline 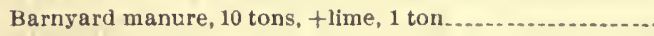 & 122 \\
\hline Manure. 10 tons & 110 \\
\hline Lime, 1 ton & 108 \\
\hline
\end{tabular}

It is obvious from the above data that cowpeas and nitrate of soda are very beneficial manures for this soil. The quantities of cowpeas and manure, as given in the table, are based on water-free substance, and in case of the former would represent, in the respective items, a little less than 6 tons and 3 tons of cowpea hay per acre. In growing a crop of cowpeas for green manure a yield of 3 tons of hay would be considered good, whereas 6 tons might be beyond what could be expected. It should be noted, in this connection, however, that the roots and stubble of the crop would probably equal 50 per cent of the weight of the tops, and that they not only possess a manurial value, but also materially improve the physical condition of the soil through their penetration of it. Acid phosphate and sulphate of potash were used at the rate of 200 pounds per acre alone and in combination with nitrate of soda and lime. They are not mentioned in the above table for the reason that they gave no appreciable increase in growth. It would seem, therefore, that neither potash nor phosphorus is required in order to increase the productivity of this soil. 
Thinking that there might be a residual effect from the fertilizer, certain of the treatments were replanted with wheat without repeating the fertilizers. In case of the untreated soil the second crop was reduced in yield to 65 per cent of the first, whereas the reduction in yield with a complete fertilizer either with or without lime fell to 36 per cent of the original yield which was produced with the fertilizer. In fact, the second crop in the baskets to which fertilizer had been originally applied was very slightly greater than was the second crop on the untreated soil, which shows that the effect of the commercial fertilizer was practically exhausted by the first crop. It is also worthy of mention in this connection that it is impossible even by repeating the fertilizer to secure as large a yield in the second or the third crop as was originally secured with the treatment in the first crop. This is probably due to the fact that the draft made upon the soil by the plants during the short period of growth is fully as great as under field conditions during the entire season, and that the crop itself leaves a residue in the soil which may be harmful to a succeeding crop of the same kind unless the soil remains unused for a sufficient length of time to admit of an oxidation or disappearance of this objectionable substance.

The commercial fertilizer above referred to as used in the field practice contains 8.6 per cent of phosphoric acid as against 3 per cent each for nitrogen and potash, and it is safe to state that this is not far from the proportion which is generally used in commercial fertilizer in the county at large. According to the census of 1899 , the annual expenditure for commercial fertilizers in Lancaster County amounts to a little more than $\$ 70,000$. From the above results it would seem probable that the percentage of phosphoric acid might be materially reduced and that of nitrogen increased with satisfactory results. The growing of cowpeas as green manure for this soil is plainly the most economical way to build it up. In fact, before the above tests were made one of the authors (F. E. B.) had already arrived at this conclusion as the result of his observations. Messrs. Root and Hurst in their report upon the soil survey of Lancaster County (1904) make the following statement:

Since stock raising is not followed in this county and adequate manurial elements can not be supplied from this source, the legume must be chiefly relied upon as an economical soil renovator. The farmers are gradually realizing the beneficial results of such crops, and a more extensive acreage is being devoted to their cultivation. It can not be pointed out too clearly how invaluable such crops are in almost all sections of the South, not only in supplying plant food to the soil, but also in improving its physical structure.

The suggestions herein made for the building up of Cecil silt loam in Lancaster County are not based solely upon the above tests but also on the fact that the results seem to be in thorough accord with the observations of experts who have visited the county and with the experience 
of the farmers themselves. It should, of course, be borne in mind that the above results are obtained with soil from a field which has a certain past history, and that the same type of soil from another field with a past history widely different from this might give results considerably at variance with it. As a rule, however, the conditions which prevail on a soil type of a certain locality are fairly uniform, there being a relatively small number of farmers that deviate from the general farming practices of the neighborhood.

It should be understood also that the conditions encountered in farm practice are different from those maintained in these experiments. The treatments when put to a field test might prove more or less effective, or, owing to excessive rainfall or drought, might fail entirely. Furthermore, the wheat plant has been used as the test of fertility in these experiments, and whether it is a safe indicator for cotton and other crops has not been determined. It is generally conceded, however, that if a soil will produce a good crop of wheat it will produce good yields of general farm crops.

Arrangements have been made to confirm the above results by actual field tests on the field from which the above soil was taken.

F. D. GaRdner, In Charge of Soil Management.

F. E. BonsteEL,

Approved :

Assistant.

JAMES WILSON,

Secretary of Agriculture.

August 1, 1905. 


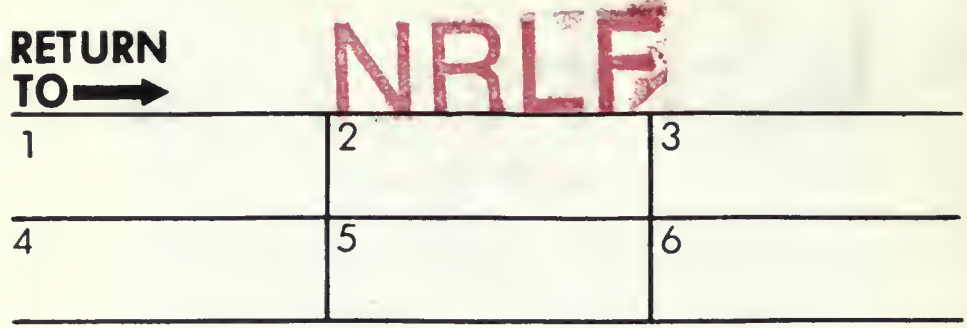

ALL BOOKS MAY BE RECALLED AFTER 7 DAYS

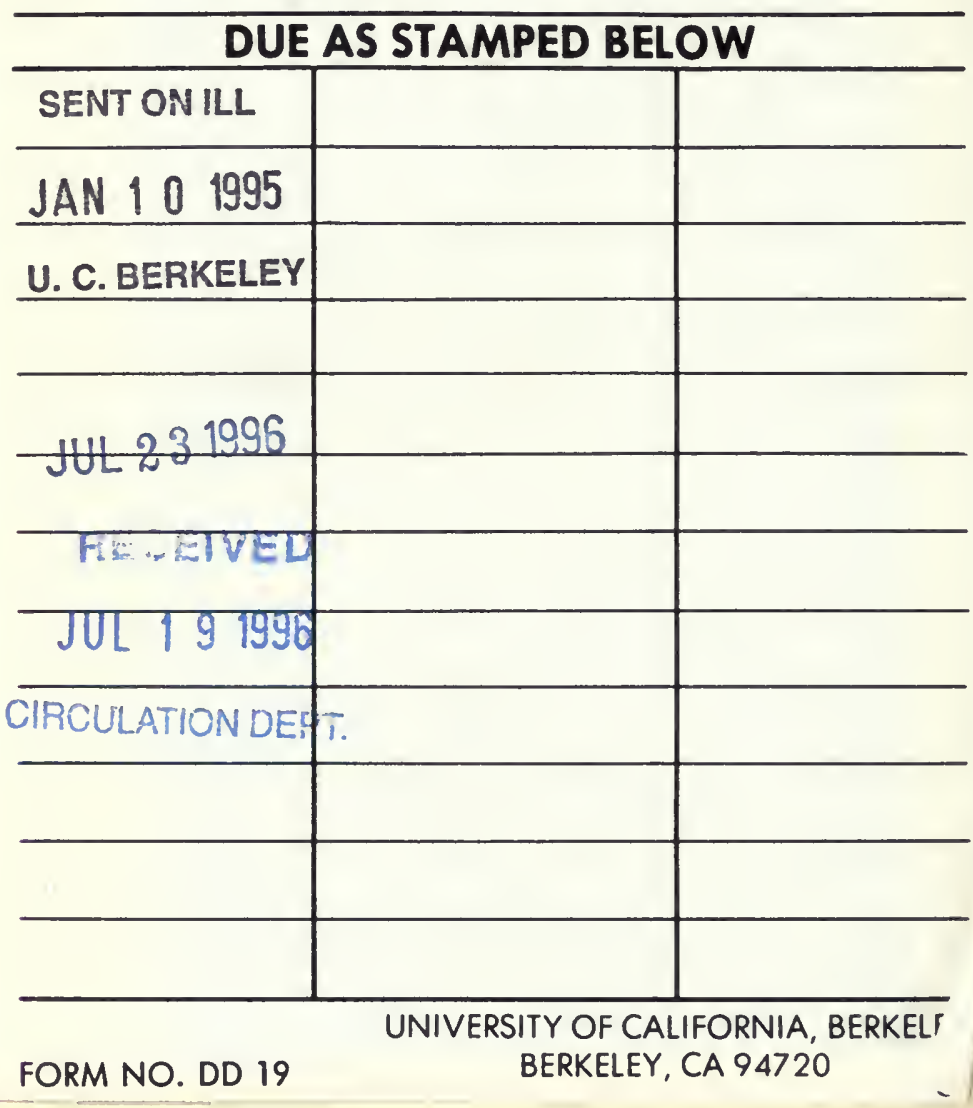




\section{YC 67891}

U. C. BERKELEY LIBRARIES

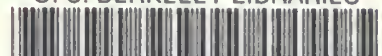

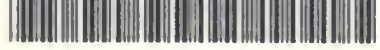
c057093926

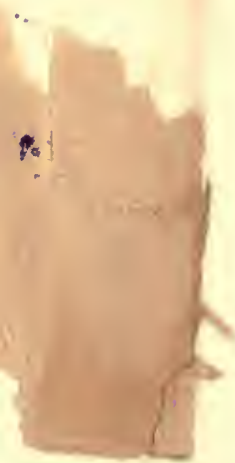

$\therefore$

a.

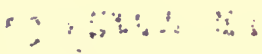


